\title{
Optimised gravity anomaly fields from along-track multi-mission satellite altimeter over Malaysian seas
}

\author{
Nornajihah Mohammad Yazid', Ami Hassan Md Din 1,2*, Abdullah Hisam Omar, Nazirah Mohamad Abdullah", \\ Muhammad Faiz Pa'suya ${ }^{5}$, Mohammad Hanif Hamden ${ }^{1}$ and Noor Anim Zanariah Yahaya ${ }^{1}$
}

\begin{abstract}
Marine gravity anomalies are crucial parameters and elements for determining coastal and ocean geoid, tectonics and crustal structures, as well as offshore studies. This study aims to derive and develop a marine gravity anomaly model over Malaysian seas from multi-mission altimetry data. Universiti Teknologi Malaysia 2020 Mean Sea Surface Model is computed based on along-track data from nine satellite missions, incorporating TOPEX, Jason-1, Jason-2, ERS-2, Geosat Follow on (GFO), Envisat-1, CryoSat-2, SARAL/AltiKa, and Sentinel-3A. The data exploited are from 1993 to 2019 (27 years). Residual gravity anomaly is computed using Gravity Software, and two-dimensional planar Fast Fourier Transformation method is applied. The evaluation, selection, blunder detection, combination, and re-gridding of the altimetry-derived gravity anomalies and Global Geopotential Model data are demonstrated. Cross-validation procedure is employed for data cleaning and quality control using the Kriging interpolation method. Then, cross-validation procedure is applied to the tapering window width 200, which adopting the GECO model denotes the optimum gravity anomaly with root mean square errors in the range of $\pm 4.2472 \mathrm{mGal}$ to $\pm 6.0202 \mathrm{mGal}$. The findings suggest that the estimated marine gravity anomaly is acceptable to be implemented in the marine geoid determination and bathymetry estimation over Malaysian seas. In addition, the results of this study are valuable for geodetic and geophysical applications in marine areas.
\end{abstract}

\section{Key points}

- Along-track altimetry data are used for mean sea surface derivation.

- Mean sea surface model is utilised in the estimation of marine gravity anomalies.

- Global Geopotential Model is crucial in the marine gravity estimation of a region.

Keywords: Marine gravity anomalies, Altimetry data, Fast Fourier Transformation, Global Geopotential Model

\section{Introduction}

Coastal areas are home to nearly half of the world's

*Correspondence: amihassan@utm.my

${ }^{1}$ Geospatial Imaging and Information Research Group (GI2RG), Faculty of Built Environment and Surveying, Universiti Teknologi Malaysia, 81310 Skudai, Johor, Malaysia

Full list of author information is available at the end of the article population, and the impacts of sea level rise (accompanied by tides, storm surges, erosion, and other effects) in the area is a significant concern in the near future (Urban et al. 2018). One of the imperative parameters required in the study of these phenomena is marine gravity anomaly. The parameter is crucial to develop the gravity model of

\section{Springer}

(c) The Author(s) 2022. Open Access This article is licensed under a Creative Commons Attribution 4.0 International License, which permits use, sharing, adaptation, distribution and reproduction in any medium or format, as long as you give appropriate credit to the original author(s) and the source, provide a link to the Creative Commons licence, and indicate if changes were made. The images or other third party material in this article are included in the article's Creative Commons licence, unless indicated otherwise in a credit line to the material. If material is not included in the article's Creative Commons licence and your intended use is not permitted by statutory regulation or exceeds the permitted use, you will need to obtain permission directly from the copyright holder. To view a copy of this licence, visit http://creativecommons.org/licenses/by/4.0/. 
the Earth and for research related to global tectonics and continental margin structure.

Conventionally, in marine areas, the airborne and shipborne were utilised to measure gravity. However, the information of gravity data are inadequate for the specified study area due to time constraints and the high cost necessitated to conduct the survey. Therefore, a better option is to use multi-mission satellite altimeters for comprehensive data acquisition, particularly for marine gravity estimations. Satellite altimetry is acknowledged as an invaluable source for providing homogeneous and economical data. Moreover, altimetry data also enable continuous, high-accuracy, high resolution, and broad coverage ocean study, making it significant for marine geodesy applications.

According to Liu et al. (2016), satellite altimetry data are utilised to compute and determine marine gravity anomaly, and it is significant in providing abundant marine gravity and seabed geophysical information. Besides, it is crucial in developing high-precision global gravity model for high-precison global gravity model for climate study and marine resources information. Moreover, Tanaka et al. (2019) implemented satellite altimetry measurements and GRACE to examine seismic gravity changes and sea-level changes associated with geoid height variability. Gravity models can be derived from ocean surface height or slope measured by satellite altimetry in the space domain (Rapp 1979; Haxby et al. 1983; Sandwell and Smith 1997; Andersen and Knudsen 1998; Hwang 1998; Fan et al. 2020).

Marine gravity field modelling depends on the accuracy and resolution of the assembled multi-mission satellite altimetry data. It is based on the following factors: (1) the precision of altimeter range; (2) the density of spatial track and along-track sampling rate; (3) the diversity of track orientation; (4) the accuracy of the modelled ocean tide corrections, particularly over coastal areas; and (5) the low-pass filters applied to the profile data (Zhang et al. 2016).

As a result, regional marine gravity anomaly over Malaysian seas is computed based on the combination of altimetry-derived gravity anomaly and Global Geopotential Model (GGM)-derived gravity anomaly data. Thus, to determine precise gravity anomaly and estimate marine geoid model, several considerations have been taken into account, including the assessment of tapered window width. Computation of residual gravity anomaly has been conducted using the remove-compute-restore technique, planar estimation of Stokes' function, and Fast Fourier Transformation (FFT) method. Subsequently, the residual gravity anomaly is combined with GGMderived gravity anomaly from satellite only (GO_CONS GCF_2_DIR_R5) and combined solutions model (GECO) to obtain full spectrum gravity anomaly data. Altimetryderived gravity anomaly has been evaluated and refined based on cross-validation approach to detect and remove outliers from the data. Then, Kriging spatial interpolation has been used to perform the $0.06^{\circ}$ integral of the altimetry-derived gravity anomaly data.

Concisely, this study demonstrates the computation and modelling of marine gravity using multi-mission satellite altimeters over Malaysian seas. The findings of this study are significant for marine geoid determination and bathymetry estimation over Malaysian seas. In addition, modelling of geodynamic phenomena like polar motion, Earth rotation, and crustal deformation can be predicted by implementing gravity data into the computations (Bogusz et al. 2015).

\section{Methodology}

\subsection{Description of the study area}

The study area is concentrated over the Malaysian marine areas, including Peninsular Malaysia, Sabah, and Sarawak, which are bordered between latitude $0^{\circ}$ to $14^{\circ}$ and longitude $95^{\circ}$ to $126^{\circ}$ (see Fig. 1).

\subsection{Data used}

\subsubsection{Along-track altimetry data}

The present Universiti Teknologi Malaysia 2020 Mean Sea Surface, known as UTM20 MSS model, developed by Hamden et al. (2021) over Malaysian seas, is applied in this study. The UTM20 MSS model is computed based on data from nine (9) satellite missions comprising TOPEX, Jason-1, Jason-2, ERS-2, Geosat Follow On (GFO), Envisat-1, CryoSat-2, SARAL/AltiKa, and Sentinel-3A, from 1993 to 2019 (27 years). ERS-1 and Geosat-3 missions are not used for this model because they are old geodetic mission that have low precision range (Andersen et al. 2015). TOPEX-class (TOPEX, Jason-1 and Jason-2) are established as a reference to ESA-class (Envisat-1 and Cryosat-2). To improve the spatial resolution of the MSS model, data from Jason-1 Phase C GM and Cryosat-2 are implemented in this study. Then, the development of the MSS model is conducted. It involves the combination of Exact Repeat Mission (ERM) and Geodetic Mission (GM) data.

To provide the highest resolution of the model, three (3) types of mission are considered in the development of the UTM20 MSS model, including Exact Repeat Mission (ERM), Interleaved Mission (IM), and Geodetic Mission (GM). Figure 1 represents along-track Sea Surface Height (SSH) for each satellite mission and along-track SSH for the combination of multi-mission satellite altimetry involved in this study. All satellite missions are adjusted to the TOPEX reference throughout the data processing phase. The multi-mission satellite altimetry data 

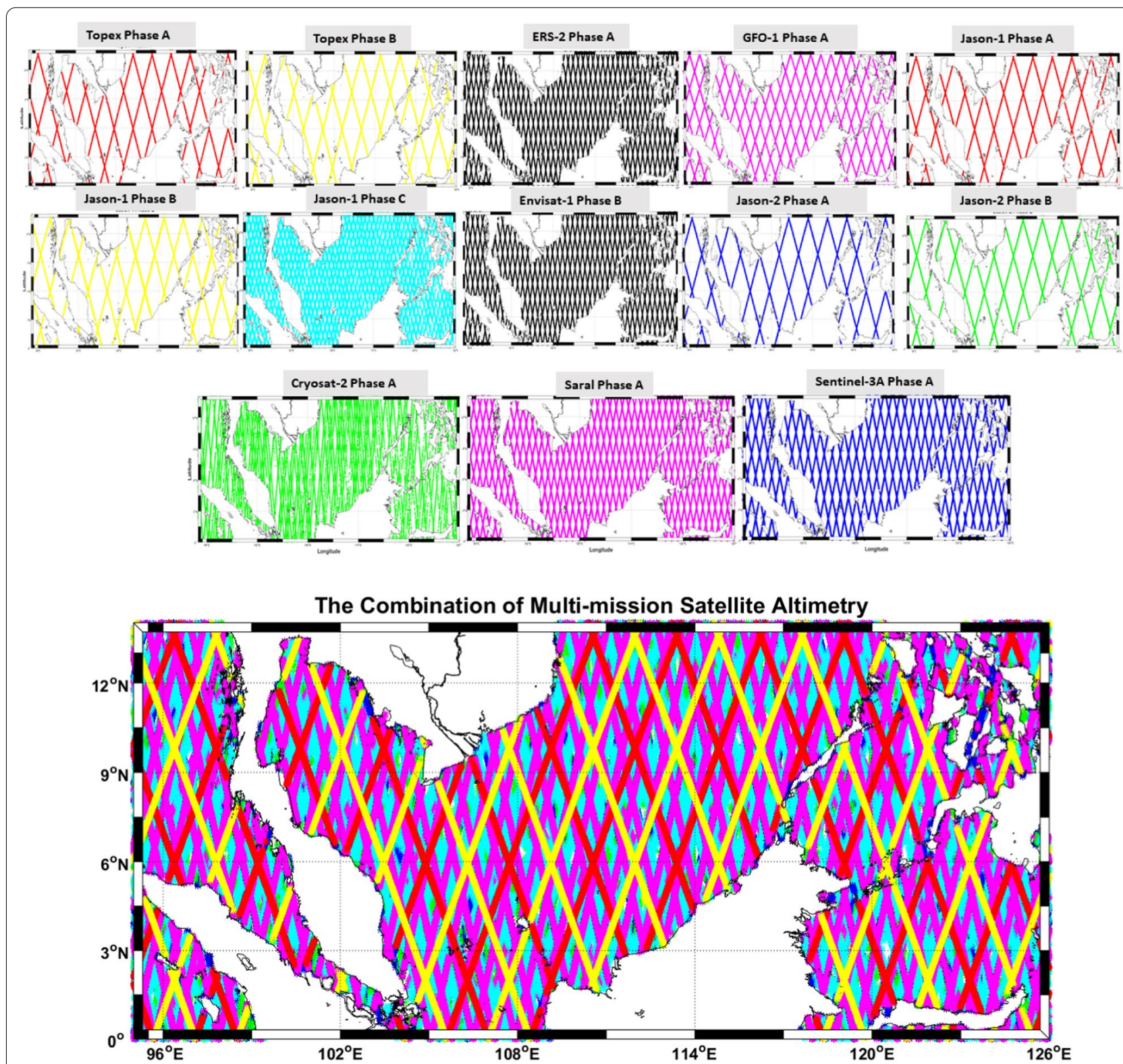

Fig. 1 (Top) Single mission of SSH along-track satellite altimetry over Malaysian seas for each phase. (Bottom) Combination of multi-mission SSH along-track satellite altimetry over Malaysian seas

implemented in determining UTM20 MSS are listed in Table 1.

Satellite altimetry data obtained in this study are presented by the Technical University of Delft (Netherlands). The data can be assessed through the Radar Altimeter Database System (RADS) server at Universiti Teknologi Malaysia (UTM), which provides the latest orbital information and geophysical corrections. Satellite altimetry data implemented in the computation have been preprocessed based on the optimal range and geophysical corrections for the Malaysian region. Most of the ranges and geophysical corrections implemented in this study are based on user manuals and gradual experiences from prior studies (Scharroo et al. 2012; Din et al. 2014, 2019; Yahaya et al. 2016; Hamid et al. 2018; Zulkifle et al. 2019).

In general, MSS model is determined by temporal average method, which depends on the following procedure: data selection and pre-processing, crossover adjustment, ERM mean track derivation, removal of seasonal variability, and data gridding. After geophysical correction and bias elimination are conducted in pre-processing section, crossover adjustment procedures are performed. 
Table 1 Summary of all altimetry data for MSS computation

\begin{tabular}{lllll}
\hline Satellite & Phase & Mission & Cycles & Period \\
\hline TOPEX & A & ERM & 012-364 & 10 Jan 1993-11 Aug 2002 \\
& B & IM & 369-481 & 20 Sep 2002-08 Oct 2005 \\
Jason-1 & A & ERM & 001-260 & 15 Jan 2002-26 Jan 2009 \\
& B & IM & 262-374 & 10 Feb 2009-03 Mar 2012 \\
& C & GM & 382-423 & 08 May 2012-12 Jun 2013 \\
Jason-2 & A & ERM & 000-303 & 04 Jul 2008-02 Oct 2016 \\
& B & IM & 305-327 & 13 Oct 2016-17 May 2017 \\
ERS-2 & A & ERM & 000-169 & 29 Apr 1995-04 Jul 2011 \\
GFO & A & ERM & 037-223 & 07 Jan 2000-17 Sep 2008 \\
Envisat-1 & B & ERM & 006-094 & 14 May 2002-22 Oct 2010 \\
CryoSat-2 & A & GM & 011-080 & 14 Jul 2010-15 Aug 2016 \\
SARAL-AltiKa & A & ERM & 001-035 & 14 Mar 2013-04 Jul 2016 \\
Sentinel-3A & A & ERM & 001-053 & 01 Mar 2016-31 Dec 2019
\end{tabular}

*IM is Interleaved Mission which is considered to be ERM data in this study

Crossover adjustment for dual-satellite missions is performed to adjust the discrepancy between two satellite observations at similar location. This procedure is significant when combining different satellite altimetry data, including ERM and GM. According to Hamid et al. (2018), crossover adjustment is a practical method to reduce errors and enhance the accuracy of the multimission satellite altimetry measurement. This could also minimise the height differences at the crossover between ascending and descending and limit track errors. Moreover, 19-year moving average method is applied in the UTM20 MSS model as recommended by Yuan et al. (2020) to certify that the residual errors of tide models are more degraded on the MSS model. Moving average technique is significant to remove the annual and semiannual variations from altimetry data and the formula is expressed in Smith (2003). For further studies, the integration of gravity anomaly with other marine and land gravity data, marine gravity anomaly data of $15 \mathrm{~km}$ from the coastal are excluded area to avoid using low-quality data near the coast. Figure 2 presents the overview of the processing flows in developing the MSS model over the Malaysian seas and the map of the UTM20 MSS model is illustrated in Fig. 3.

\subsubsection{Global marine gravity field from DNSC08, DTU10, DTU13, DTU15, DTU17, and Sandwell models}

To evaluate the derived gravity anomaly, six (6) global marine gravity fields from DNSC08, DTU10, DTU13, DTU15, DTU17, and Sandwell models from along-track altimetry data with 92,934 gravity points are used in the validation and evaluation processes. Hence, the optimal and relevant derived gravity anomaly are cross-validated to detect and remove blunders.

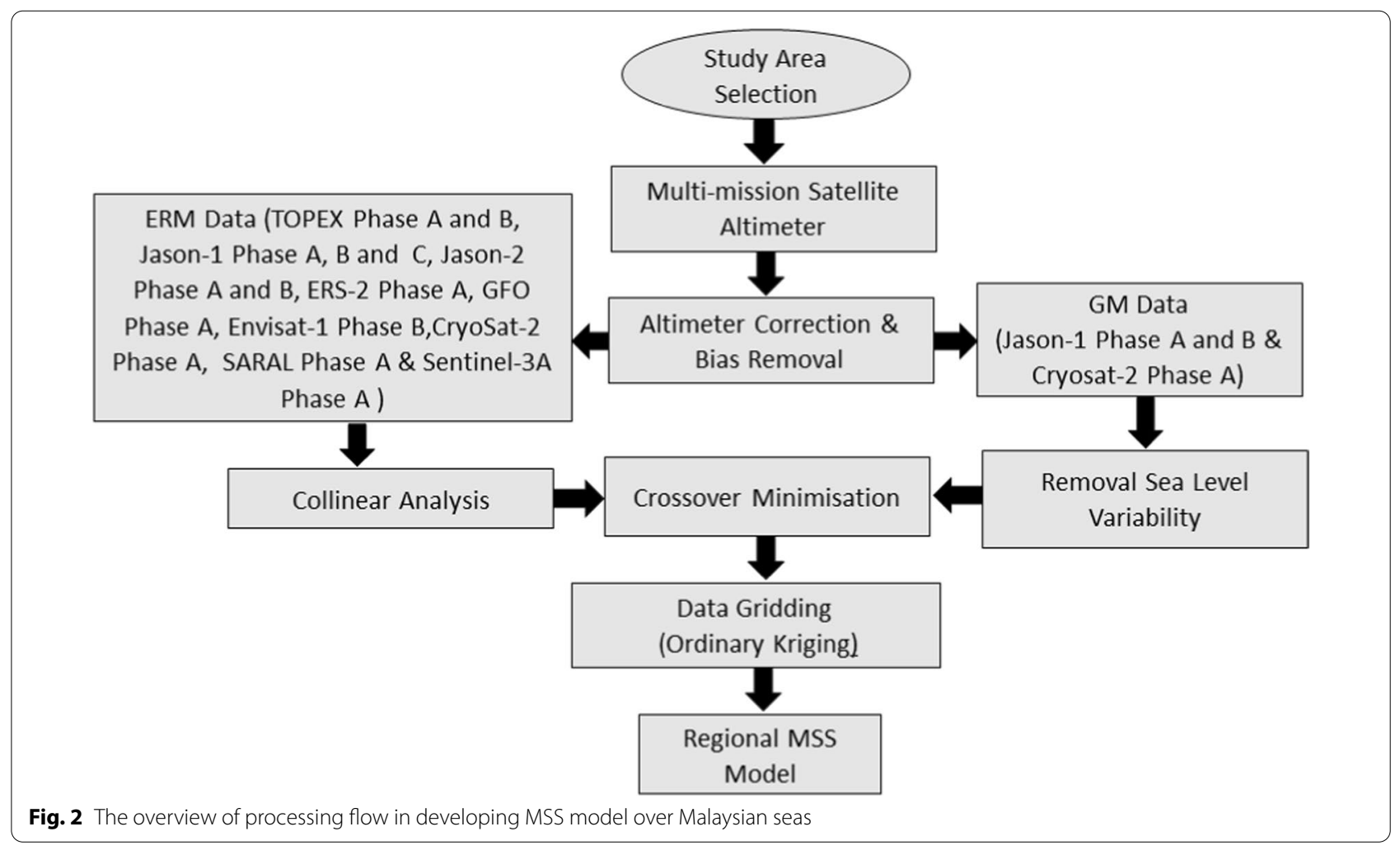




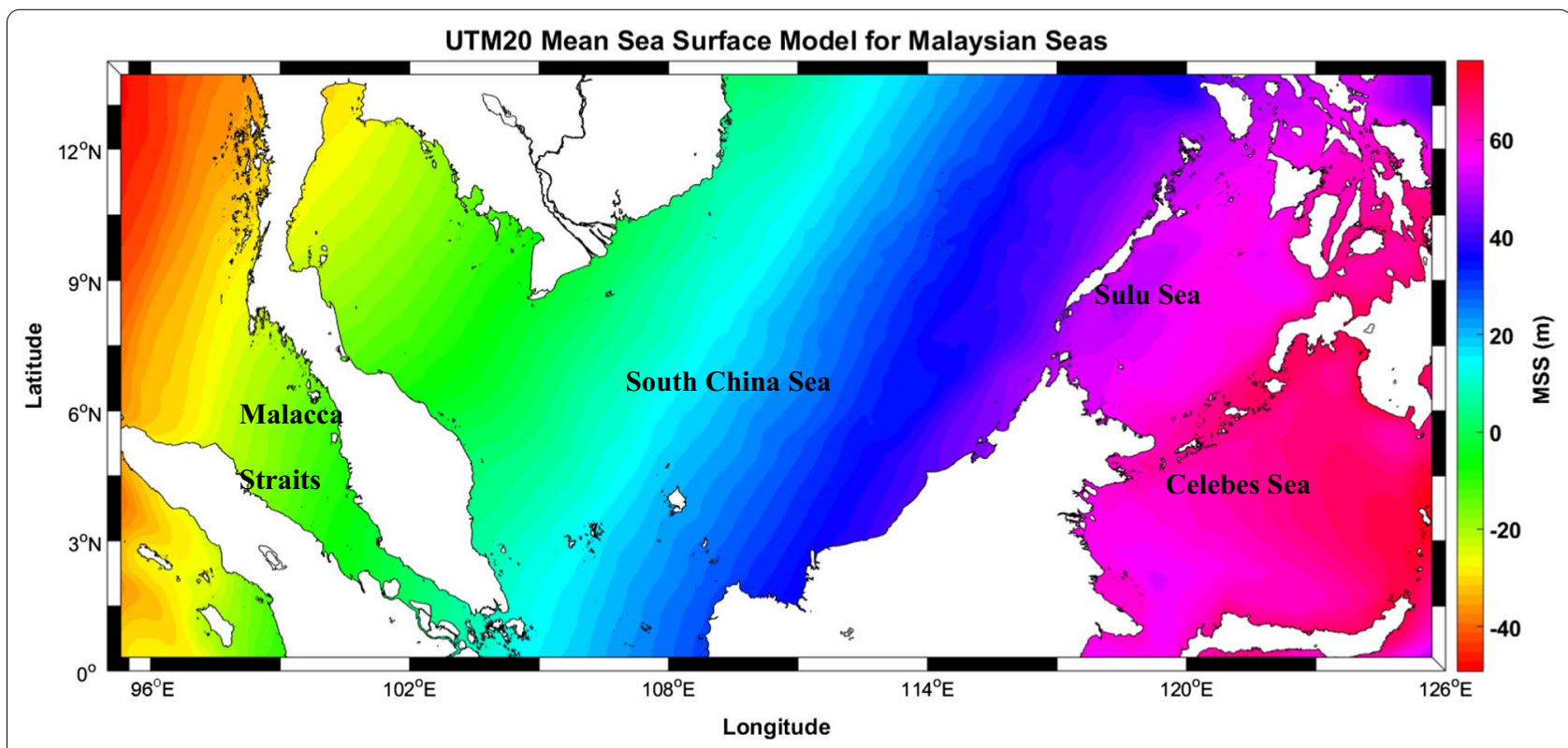

Fig. 3 The map of the UTM20 mean sea surface model (Hamden et al., 2021)

\subsubsection{Satellite-derived gravity data from satellite-only and combined solutions}

The importance of GGM in geoid computation has long been recognised, and this has resulted in the continuous development of new GGM. Efforts in developing GGM using satellite data has started since 1970s with the GEM-1 model developed by NASA/Goddard Space Flight Centre. Up until now, there are more than hundreds of GGMs available with free access provided to the scientific community. The International Centre for Global Earth Models (ICGEM) collects all existing GGMs and makes them publicly available on their website (http://icgem.gfz-potsdam.de/ ICGEM/) (Barthelmes and Köhler 2012), where any interested users can download. The methodology of evaluating the appropriate GGM-derived gravity-related fields to be used for geoid computation in any region (in our case, the geoid for Malaysian seas) is necessary as it is a standard procedure, particularly for geoid computation using remove-restore technique (Karpik et al. 2016).

Based on the evaluation with airborne-derived data from the Department of Survey and Mapping Malaysia, the satellite-only and combined solutions from GO_ CONS_GCF_2_DIR_R5 and GECO model represent the optimal and appropriate Global Geopotential Models (GGMs). GO_CONS_GCF_2_DIR_R5 is a GOCE satellite-only model based on a full combination of GOCESGG (Satellite Gravity Gradiometer) and GOCE-SST (Satellite-to-Satellite Tracking) that also encompasses GRACE (Gravity Recovery and Climatic Experiment) and LAGEOS (Laser GEOdynamics Satellite) data (Bruinsma et al. 2013). Besides, this model was attained by the direct approach with maximum degree/order, 300 of the harmonic expansion.

However, GECO model was developed by Polytechnic University of Milan in 2015 up to a maximum degree/ order 2190 of the harmonic expansion. For the highfrequency gravity signal, GOCE-TIM-5R was used in conjunction with EGM2008, which provides precision enhancement at low and middle frequencies (Gilardoni et al. 2016). Thus, these models are applied and serve as the main parameters in deriving gravity anomaly from multi-mission satellite altimeters.

\section{Methodology}

\subsection{Residual sea surface height derivation}

This section describes the methodology utilised and the data processing strategies applied in this study to compute marine gravity anomaly over Malaysian seas using altimetry data. The overall flow chart for computing marine gravity anomaly using the 2D FFT method is shown in Fig. 4.

Residual sea surface height, $h_{\text {residual }}$, can be considered as residual geoid height representing the medium wavelength of the geoid height signal, which is the subsidiary computed quantity from altimetry measurements. It is crucial in gravity anomaly computation. According to Salam (2005), residual sea surface height is computed from the difference of mean sea surface and GGMderived geoid height, where geoid heights, $N$, approximately corresponds to the mean sea surface heights derived from satellite altimeter. 


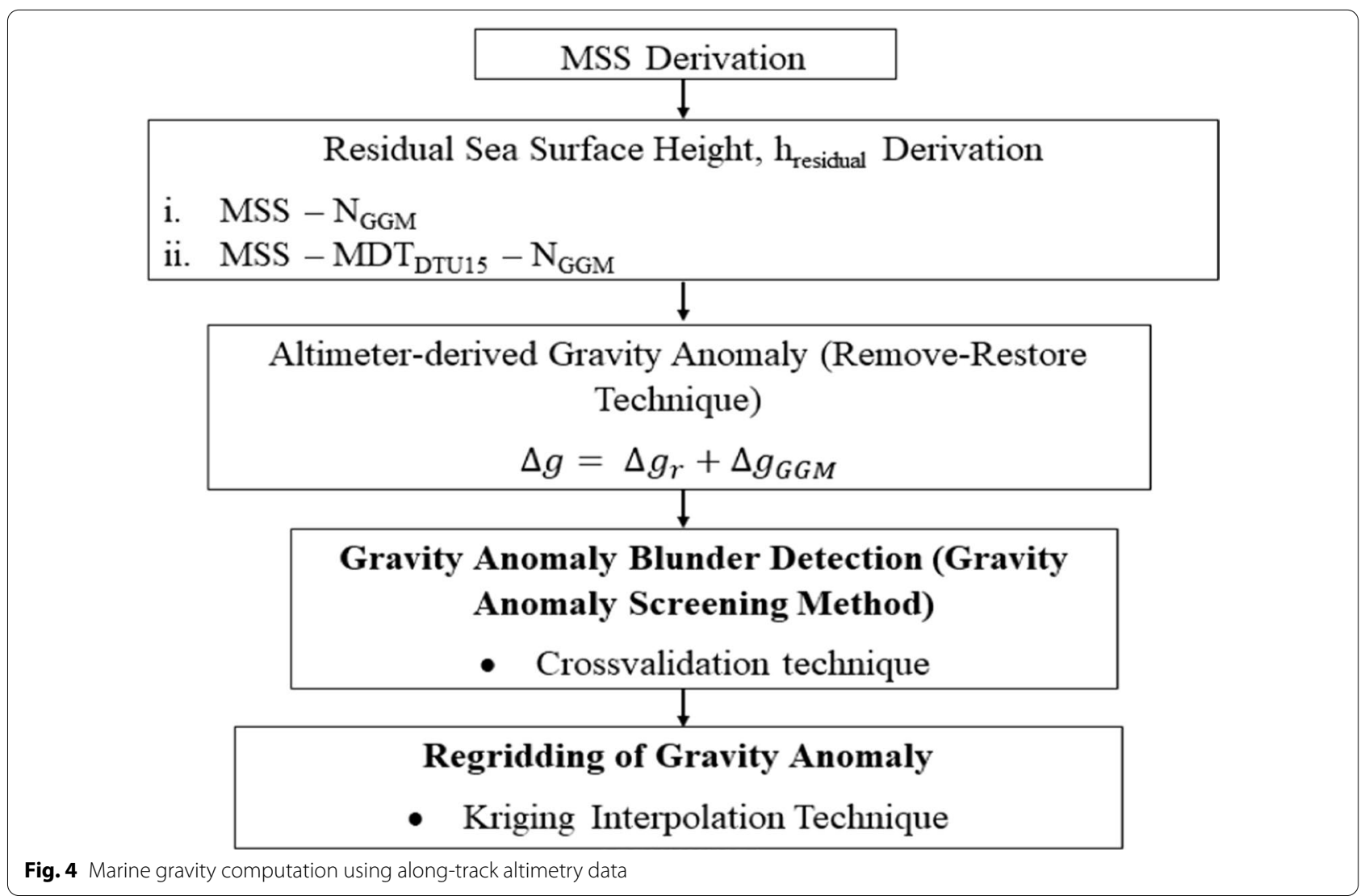

The residual sea surface height is computed by removing geoid height quantities from the mean sea surface. The process of removing long-wavelength geoid height is performed using the global geoid height from satellite-only and combined GGM solutions; GO_CONS GCF_2_DIR_R5 and GECO model, involving the remove-compute-restore method. This method has also been applied by Nguyen et al. (2020) in their calculation and determination of marine gravity using altimetry data. Hence, the approach is applied and assessed in the derivation of residual sea surface height and can be expressed as follows:

$$
h_{\text {residual }}=M S S-N_{G G M}
$$

where, $h_{\text {residual }}$ is defined as the residual sea surface height, MSS is the mean surface height derived from along-track altimetry data, $N_{G G M}$ is described as the GGM-derived geoid height (from GO_CONS_GCF_2_ DIR_R5 and GECO model). This method is used to assess and evaluate the accuracy of residual sea surface height. Subsequently, the residual sea surface height data is utilised to derive marine gravity anomalies over Malaysian seas.
Removing geoid field based on GGM provides residual field that can be identified as reference field, which is statistically more harmonised and smoother than the entire field. The effect of removing the reference is that the gravity information outside the data area is indirectly accounted for, and it will result in low correlation distance of covariance functions (Andersen 2013).

\subsection{Determination of marine gravity anomalies using the 2D FFT method}

Based on previous studies described by several researchers, it is highly recommended to exploit an abundance of altimetry data to estimate gravity anomalies. Discussions pertinent to this topic are presented as follows.

For instance, Andritsanos (2000) and Vergos (2002) mentioned that employing an abundance of data in gravity field estimation indicates better performance in the frequency domain to expedite the computation process. The frequency domain, also known as spectral approach, presents a time-efficient approach of processing abundance datasets and yielding similar results for numerical integration (Knudsen 1993; Tziavos et al. 1997, 1998).

It is now recognised that altimetry data can be utilised to estimate marine gravity anomaly. In this study, the altimetry data employed is the residual sea surface 
height, $h_{\text {residual }}$. The $h_{\text {residual }}$ derived using along-track altimetry data is used to estimate gravity anomaly, which is then used as input data in marine geoid computation utilising the remove-compute-restore technique.

The residual gravity anomaly is derived using the GRAVSOFT Fourier domain programs in either planar or sphere implementing discrete Fast Fourier Transform algorithm to estimate the numerous integrals of physical geodesy. The continuous two-dimensional Fourier transformation can be explained as (Forsberg and Tscherning 2008):

$$
\begin{aligned}
& F(g)=F\left(k_{x}, k_{y}\right)=\iint g(x, y) e^{-i\left(k_{x} x+k_{y} y\right)} d x d y \\
& F^{-1}(g)=g(x, y)=\frac{1}{4 \pi^{2}} \iint G\left(k_{x}, k_{y}\right) e^{i\left(k_{x} x+k_{y} y\right)} d k_{x} d k_{y}
\end{aligned}
$$

where $g$ and $G$ represent gravity anomaly data. However, $g$ is in the space domain and $G$ is in the spectral domain, respectively. Then, $k$ denotes the wavenumbers. Basically, FFT data and parameter must be in periodic and represented on a finite grid interval, and the continuous transform integral procedure is estimated in each direction by the fundamental discrete Fourier transform, as follows:

$$
\begin{aligned}
& G(n)=\sum_{k=0}^{N-1} g(k) e^{-2 \pi i \frac{k n}{N}} \quad \text { for } n=0,1, \ldots, N-1 \\
& g(k)=\frac{1}{N} \sum_{n=0}^{N-1} G(n) e^{-2 \pi i \frac{k n}{N}} \quad \text { for } k=0,1, \ldots, N-1
\end{aligned}
$$

Continuous estimation with discrete Fourier Transforms provides an increase to the difficulty of numbers, such as periodic effects Conventionally, these difficulties can be prevented by creating a data window, such as implementing a cosine taper to the data, where data near to the edge of the grid is multiplied by a function $w$ decaying from 1 to 0 as a cosines curve. Otherwise, the implementation of zero-padding normally good in physical geodesy. Hence, zero-padding is applied for the major Fourier programs like GEOFOUR programs (GEOFOUR program is implemented in the computation of residual gravity anomaly using altimetry data). Normally, the zero-padding is organised by specifying the number of points along the grid margin where the computed data should efficiently close to zero. Figure 5 illustrates the zero-padding of grid procedure.

The task to obtain gravity anomaly in this study has been accomplished using GRAVSOFT software (Forsberg and Tscherning 2008). Equations (2) until (5) are implemented in GRAVSOFT software based on 2D Fast

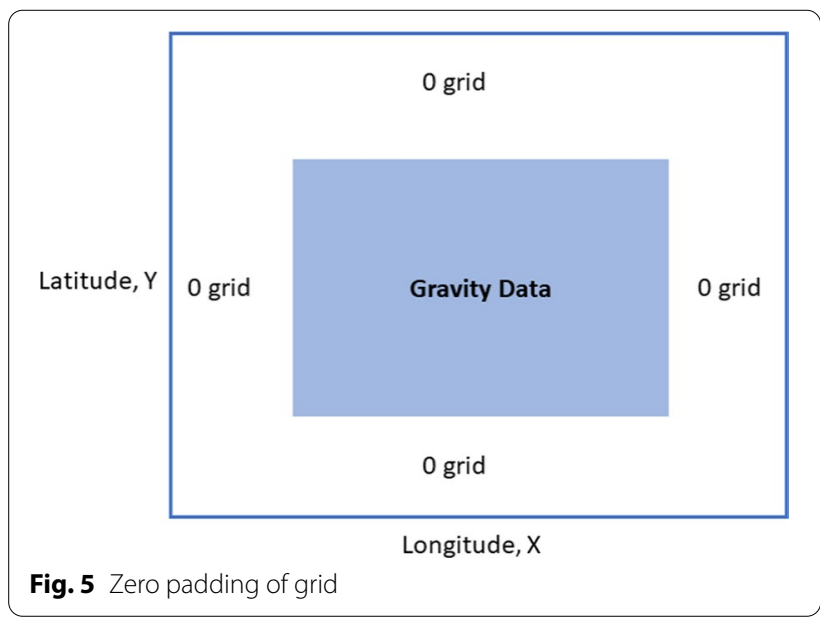

Fourier Transformation, which is required for computing residual gravity anomalies. The assessment and evaluation of the computed residual sea surface height, $h_{\text {residual }}$, are implemented in these equations.

Previously, GRAVSOFT software was for regional and local gravity field modelling, for example, geoid determination, computations of the vertical deflections, and enhancement of gravity anomalies from satellite altimetry. This software was established in the 1970s at the Geodetic Institute, later on its descendant, Geodetic and Geophysical Institute, University of Copenhagen, together with the National Survey and Cadastre of Denmark. Moreover, the GRAVSOFT programs performs fundamental operations of physical geodesy, fundamental arithmetic, and data files operations in point or grids formats. One of the modules in GRAVSOFT named Geofour, which is a routine program that can be employed for the computation of gravity anomaly using the FFT technique. The contributions of GGM is to provide low frequencies gravity field spectrum, whereby the contribution of GGM to the gravity field are determined depending on the coefficients computed in the spherical harmonic expansion configuration of the Earth's disturbing potential (Vergos 2002). However, the altimetry-derived gravity anomaly contributes to the medium frequencies during the gravity anomaly computation.

The implementation of Geofour gravity anomaly computation requires tapered window width (TWW) to be applied accordingly. This approach is performed to obtain accurate residual gravity anomaly results. TWW is defined as the width of the cosine-tapered window zone shown in grid points. According to Pilz et al. (2012), the mathematical principles entail an infinitely long time series to accomplish Fourier transform; hence, such windowing will initiate the Fourier transform method to acquire non-zero values, particularly at lower frequencies 
(commonly called spectral leakage, i.e., some frequencies manage to leak to other frequencies).

Multiplying the data windows by a 'taper' is a regular exercise before performing the Fourier transform method. The taper comprises an operation that efficiently decays the residual gravity data to zero, closing the ends of each window. It is designed to minimise the consequences of discontinuation between the beginning and the last part of the time series. Even though spectral leakage is inevitable, it can be reduced by transforming the shape of the taper function in a way to minimise strong discontinuation close to the edges of the window (Pilz et al. 2012).

Mathematically, the cosine taper is specified with respect to time, $t$, and taper ratio, $a$. The cosine window denotes an effort to set the data efficiently to zero at the borders while not significantly decreasing the level of the windows transformed. The tapering will indicate the next consequence of decreasing in spectral power leakage from the spectral peak to the frequencies by far (Pilz et al. 2012). Based on Table 2, the TWW setting is selected randomly based on the data distribution. Generally, it is complex to present the recommendations with tapers for use in any particular situation (Bingham et al. 1967). Thus, in this study, the tapering window width is selected and stopped until it reaches 200 as the taper starts to decay to zero value and closes the end of each window. Two parameters are changed in the computations: tapering window width and removing the mean value from the input anomalies. The tapering window is utilised to eliminate the periodicity effect, which is related to the discrete Fourier transform. According to Forsberg and Tscherning (2008), this can be avoided by zero-padding or windowing the data on the borders (edges).

Table 2 The tapering window width for gravity anomaly computations

\begin{tabular}{ll}
\hline No & $\begin{array}{l}\text { Tapering } \\
\text { Window Width } \\
\text { (TWW) }\end{array}$ \\
\hline 1 & 5 \\
2 & 10 \\
3 & 20 \\
4 & 50 \\
5 & 70 \\
6 & 100 \\
7 & 125 \\
8 & 150 \\
9 & 170 \\
10 & 200 \\
\hline
\end{tabular}

\subsection{Restoring the long wavelength gravity anomaly}

The reference gravity model used in this study is the GGM model from satellite-only and combined solutions model from GO_CONS_GCF_2_DIR_R5 and GECO model. Hence, the full free-air gravity anomaly obtained is referred as $\Delta \mathrm{g}_{\text {full }}$. The residual gravity anomaly, $\Delta \mathrm{g}_{\text {altimeter }}$, computed by Geofour is combined with the GGM-derived gravity anomaly, $\Delta \mathrm{g}_{\mathrm{GGM}}$, as shown below:

$$
\Delta g_{\text {full }}=\Delta g_{\text {altimeter }}+\Delta g_{G G M}
$$

\subsection{Cross-validation procedure}

In statistical terms, the cross-validation approach can be interpreted as the separation of data samples into sub-samples, so that the analysis can be primarily accomplished on a single sub-sample. Although, further sub-samples are kept "blind" for further use in the verification process of preliminary analysis. The cross-validation theory was initiated by Geisser and Eddy (1979).

The cross-validation approach estimates the value of $\Delta g$ at data point by applying the values from the neighbouring data points and neglecting the value at the point in question (Kiamehr 2010). All data in the database can be evaluated by employing this procedure. On the other hand, points that are inadequately estimated by neighbouring data may be a symptom of anomalous values. Therefore, the cross-validation technique is applied in this study sequentially to validate the computed gravity anomaly data before determining marine geoid height.

In this study, the derived gravity anomaly from altimetry data that representing the lowest root mean square error (RMSE) are selected to perform a cross-validation procedure. Then, the cross-validation procedure is conducted repetitively on estimated gravity anomalies $\left(\Delta g_{\text {reduced }}\right)$ in the database. There are three (3) techniques that have been followed:

i. Eliminate the known point form dataset (the predicted point)

ii. The remaining datasets (surrounding points) are employed to estimate the value of the previously removed point via interpolation method.

iii. The error is computed by comparing the predicted and observed values at a similar point. The difference between the estimated gravity anomaly (interpolated value), $\Delta g_{\text {pre }}$, and the estimated gravity anomaly (known value), $\Delta g_{\text {estimated }}$, provide the information of interpolated residual for gravity anomaly, $\Delta g_{\text {residual }}$

There are numerous inaugurated gridding techniques, for instance, Kriging (Krige 1951), least-squares collocation (Moritz 1972), Bjerhammar method (Bjerhammar 
1973), frequency domain approach (Vermeer 1992), and Inverse Distance, which can be employed with cross-validation approach. However, the technique that represents the minimum standard deviation for data cross-validation is highly recommended for final gridding. To estimate the final gravity grid, one assessment was evaluated by Kiamehr (2010) by employing different gridding algorithms, such as Inverse Distance, Kriging, Triangulation, Nearest Neighbour, Moving Average, and Local Polynomial. Therefore, the cross-validation of data is utilising the different interpolation approaches represents the Kriging method with the linear variogram. Variogram represents the minimum standard deviation value between the estimated and original values.

Besides, the different gridding techniques, which have been examined by Sulaiman (2016), are among the most suitable interpolation technique. Based on the minimum standard deviation, three (3) interpolation techniques from Kriging, Inverse Distance Weighting, and Nearest Neighbour are examined. The results show that the Kriging technique represents the minimum standard deviation. Due to this reason, the Kriging gridding and interpolation technique is selected to interpolate gravity anomaly in the grid.

Subsequent to the cross-validation and gridding process, one histogram is constructed to illustrate the absolute values of differences between the estimated and the original reduced gravity anomaly $\left(\Delta g_{\text {reduced }}-\Delta g_{\text {estimated }}\right)$. Where the abrupt change of slope is clearly illustrated in the residual values below; thus, the expected value can be specified. The example of the residual histogram results before the cross-validation process of residual altimetryderived gravity anomaly is illustrated in Fig. 6. Based on the histogram in Fig. 6, the residual of altimetry-derived gravity anomaly plummet at $5 \mathrm{mGal}$. Thus, any residual values greater than $\pm 5 \mathrm{mGal}$ are considered as outliers and removed. The analysis and validation of the gravity data are performed based on a cross-validation scheme (Kiamehr 2010).

\section{Results and discussion}

\subsection{Residual marine gravity anomalies from ten (10) examined tapering window widths}

Gravity data play an important role in the determination of local marine geoids. In this study, the residual gravity anomalies are computed by applying the residual sea surface height results from Eq. 1. The residual gravity anomalies are derived using the Geofour program from GRAVSOFT software. Geofour program are developed to compute and determine the gravity field with the Fast Fourier Transformation (FFT) planar approach. Ten (10) tapering window widths have been used to compute residual gravity anomaly, as illustrated in Fig. 7. Where Fig. $7 \mathrm{a}-\mathrm{j}$ represent the distributions of residual gravity anomaly from tapering window widths of $5,10,20,50$, $70,100,125,150,170$ and 200, respectively.

Tapering window widths involve multiplying the data windows by a taper before operating the Fourier Transform. Taper performs as a function to decay each window to zero near the end. A small block of tapering window width presents the narrow rectangular window. This

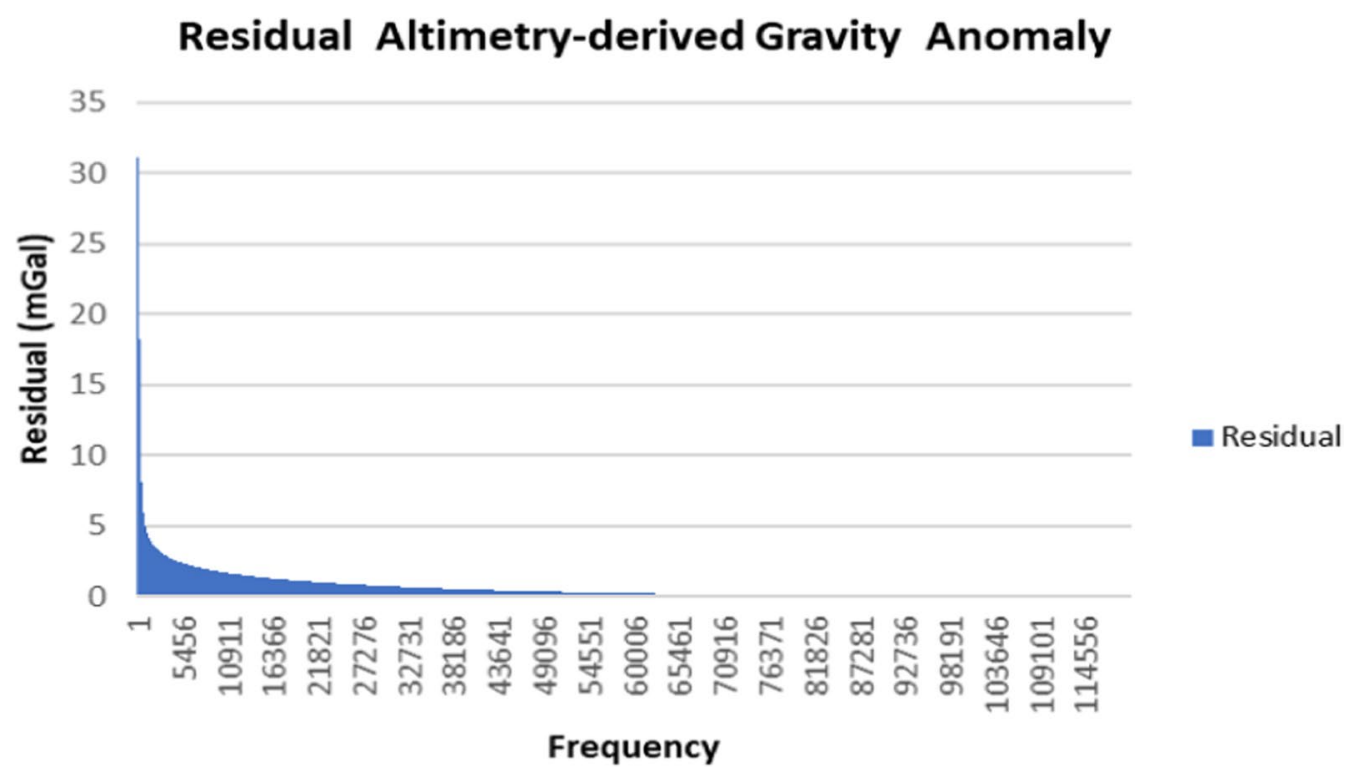

Fig. 6 The residual histogram before the cross-validation process of residual altimetry-derived gravity anomaly 


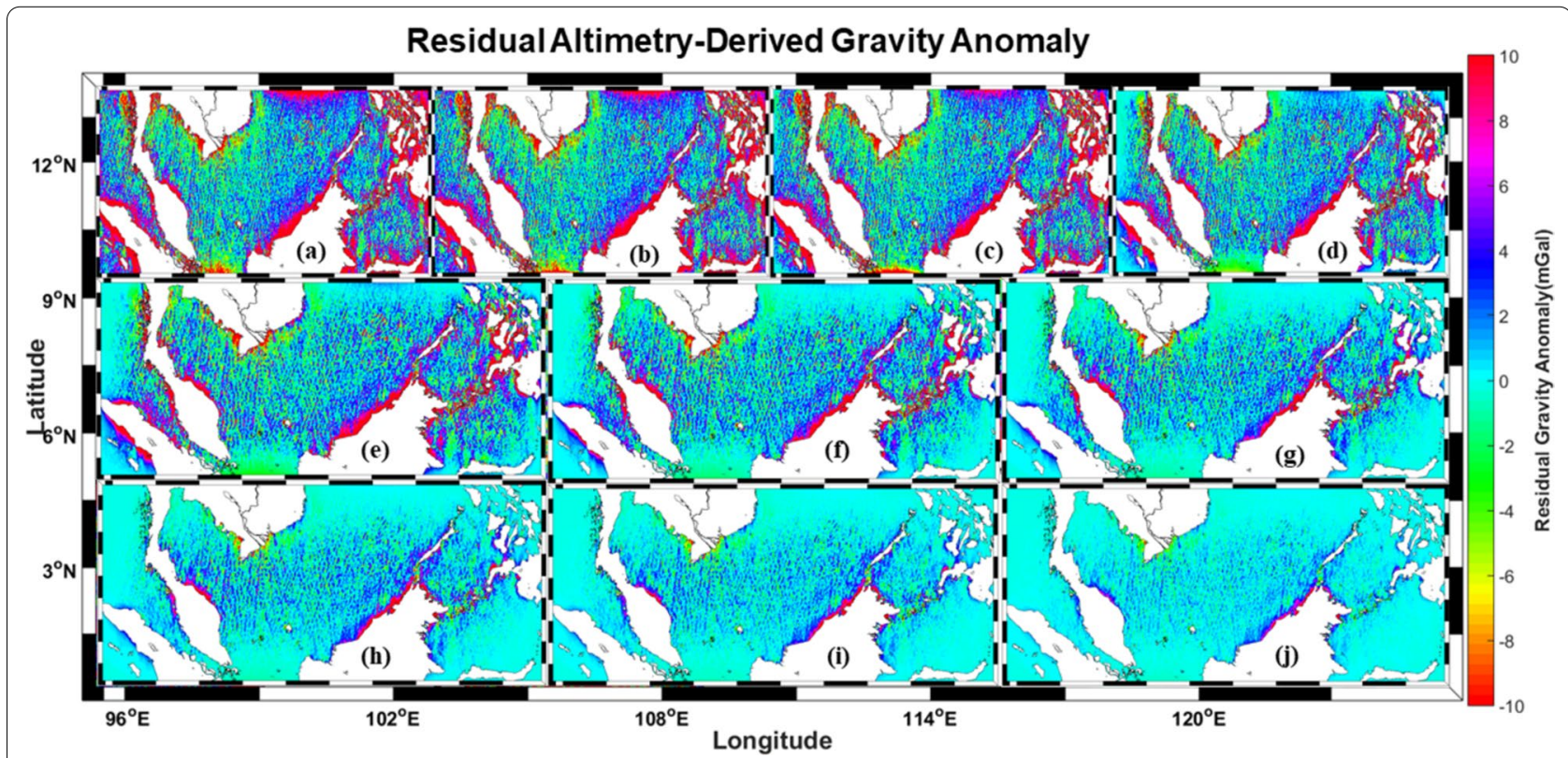

Fig. 7 Residual gravity anomaly distributions from tapering window width 5 (a), tapering window width 10 (b), tapering window width 20 (c), tapering window width $50(\mathbf{d})$, tapering window width $70(\mathbf{e})$, tapering window width $100(\mathbf{f})$, tapering window width 125 (g), tapering window width 150 (h), tapering window width 170 (i) and tapering window width 200 (j)

indicates that the Fourier transform becomes wider; hence, more leakage is accomplished.

Referring to Fig. 7, as the tapering window width increases, the distributions of residual gravity anomalies approach zero value. The decay process of the derived-residual gravity anomaly starts at tapering window width with block 50 . Hence, at the end of tapering window width with block 200 , the residual gravity anomaly almost completely decayed to zero near the

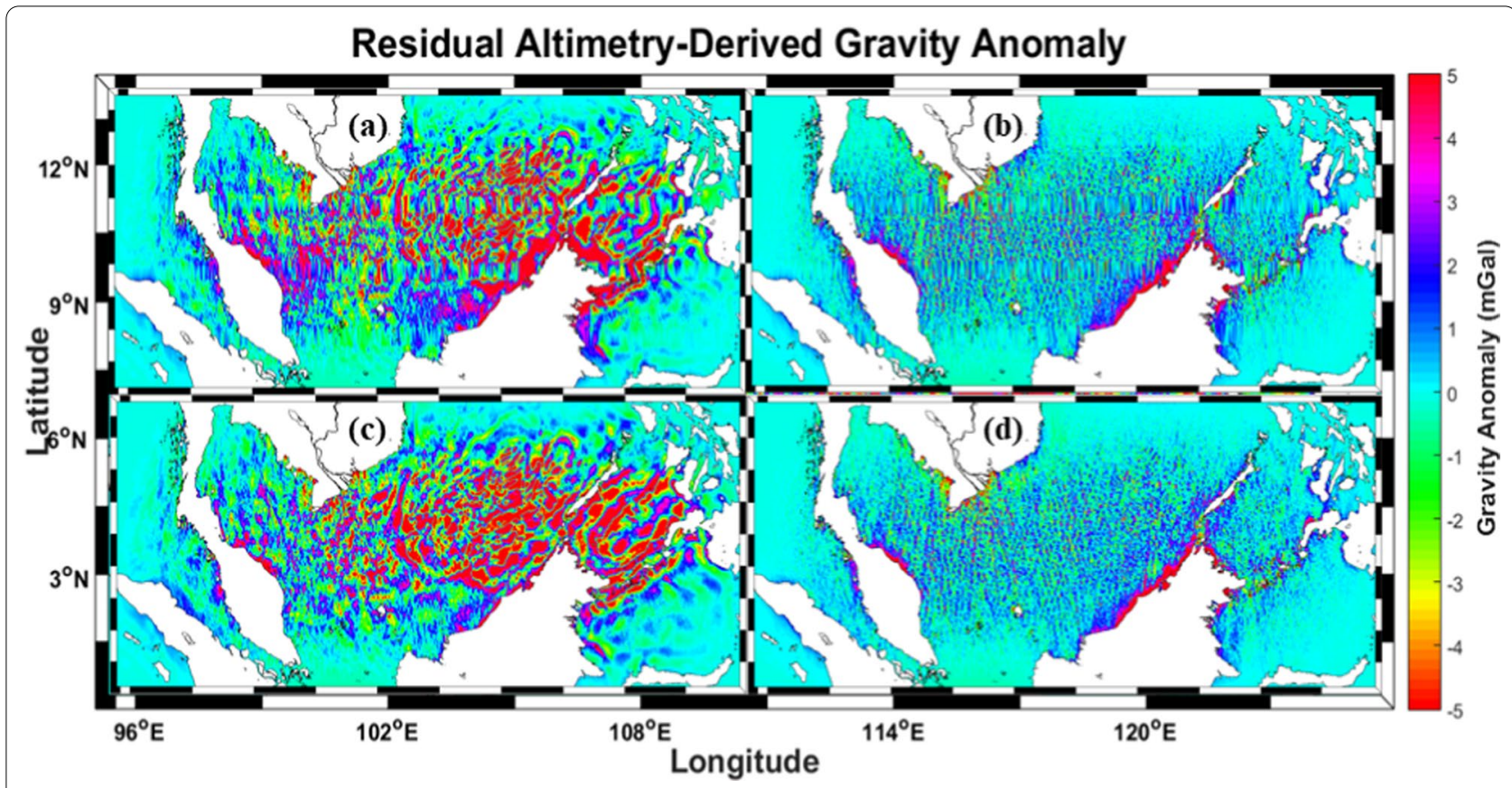

Fig. 8 Residual altimetry-derived gravity anomaly based on EGM96 (a), EGM2008 (b), GO_CONS_GCF_2_DIR_R5 (c) and GECO 
end of each window, and the rectangular window becomes wider.

There have been other assessments for altimetryderived residual gravity anomaly at tapering window width 200 with the implementation of GGM from EGM96, EGM2008, GO_CONS_GCF_2_DIRR5, and GECO, as shown in Fig. 8. In Fig. 8, the distributions of the residual gravity anomaly map for EGM2008 and GECO are almost similar, while the distributions of the residual gravity anomaly map for GO_CONS GCF_2_DIR_R5 is almost identical to the residual gravity anomaly map for EGM96. The reason for this is that degree and order plays a significant role in modelling. EGM2008 model and GECO model published high-degree global geopotential models, $2190^{\circ}$, while GO_CONS_GCF_2_DIR_R5 published low-degree global geopotential model, $300^{\circ}$, and $360^{\circ}$ degree for EGM96 model. EGM2008 and GECO have relatively higher spatial resolutions. These models are derived by combining satellite gravimetric data, terrestrial and marine gravity data depending on spherical harmonic functions with full expansion degree and order of $2190^{\circ}$ or $2159^{\circ}$ (Wu et al., 2021). Furthermore, the residual altimetry-derived gravity anomaly over coastal areas are widely different compared to the open sea, as seen in Fig. 8.

\subsection{The evaluation of full spectrum gravity anomalies with global marine gravity anomalies models}

The GGM-derived gravity anomaly from GO_CONS GCF_2_DIR_R5 and GECO model are combined with the residual altimetry-derived gravity anomaly (starting from tapering window width with block 5 to 200) to provide the full information of gravity anomaly. Then, these altimetry-derived gravity anomalies data are evaluated and compared with the global marine gravity anomalies models from DNSC08, DTU10, DTU13, DTU15, DTU17, and Sandwell V29.1.The statistical analysis of the altimetry-derived gravity anomaly evaluation is depicted in Table 3.

As illustrated by statistical analysis in Table 3, it indicates that the RMSE and standard deviation values decrease with increasing tapering window width (starting tapering window width 5 until 200). This result is related to the results discussed in Sect. 4.1, which is the residual altimetry-derived gravity anomaly are decayed to zero near the end of each window with the increasing block.

Moreover, RMSE values based on the implementation of GECO model from tapering window width 200 presents the lowest values in the ranges of $\pm 4.3317 \mathrm{mGal}$ to $\pm 6.0726 \mathrm{mGal}$ after verified with global marine gravity anomaly from DNSC08, DTU10, DTU13, DTU15, DTU17, and Sandwell models. However, there is a significant difference in RMSE value from the $\mathrm{GO}_{-}$ CONS_GCF_2_DIR_R5 model for tapering window width 200 with respect to their evaluation and verification with global marine gravity anomaly model that yielding RMSE value in the range of $\pm \pm 18.5430 \mathrm{mGal}$ to $\pm 19.2715 \mathrm{mGal}$. Hence, based on this results, it can also prove the statement from Yazid et al. (2016), who mentioned that the combined GGMs solutions provide better fit to terrestrial gravity data than satellite-only models, is accurate. Besides, these combinations lead towards the best approximation of the Earth's gravitational field. By combining all the gravity data, some limitations on higher degree expansion can be diminished. However, errors in terrestrial data remain.

\subsection{Cross-validation results for marine gravity anomalies from tapering window width 200}

As discussed in Sect. 4.2, the altimetry-derived gravity anomaly using tapering window width 200 presents the lowest RMSE, indicating good accuracy among other derivations. Hence, these derivations are selected to perform the cross-validation procedure since it is significant to detect and remove blunders in the altimetry-derived gravity anomaly data. Table 4 illustrates the statistical analysis for altimetry-derived gravity anomaly before and after the cross-validation procedure.

Based on the analysis, the average differences, standard deviation, and RMSE values are decreased by approximately $\pm 0.0524 \mathrm{mGal}$ to $0.0845 \mathrm{mGal}$. After performing the cross-validation procedure. Due to this result, altimetry-derived gravity anomaly with tapering window width 200 is selected as the altimetry-derived gravity anomaly model over Malaysian sea with RMSE values of \pm 4.2472 $\mathrm{mGal}$ to $\pm 6.0202 \mathrm{mGal}$ with respect to the evaluation and verification with global marine gravity anomaly from DNSC08, DTU10, DTU13, DTU15, DTU17, and Sandwell.

Moreover, the gravity anomalies in this paper have marked differences with respect to the anomalies from Scripps Institution of Oceanography (SIO) V29.1 about $\pm 6 \mathrm{mGal}$. In reference to Sandwell et al. (2014), this model was developed from 70 months of free-air marine gravity anomalies calculated from CryoSat- 2 data and Jason-1 GM data, which are augmented by older altimetry calculations from GeoSat and ERS-1 with a 31-month operating period. Hence, these altimetry data determine more short-wavelength gravity features. However, as compared to DNSC08, DTU10, DTU13, DTU15 and DTU17 model published by Denmark Technical University (DTU), they are based on multi-mission satellite altimetry and include up to 10 different satellites with an operating period of 12 to 20 years. 
Table 3 The statistical analysis of altimetry-derived gravity anomaly (units are mGal)

\begin{tabular}{|c|c|c|c|c|c|c|c|c|c|c|}
\hline \multicolumn{6}{|c|}{ GECO } & \multicolumn{5}{|c|}{ GO_CONS_GCF_2_DIR_R5 } \\
\hline TWW & Min & Max & Average & Std Dev & RMSE & Min & Max & Average & Std Dev & RMSE \\
\hline \multicolumn{11}{|c|}{ DIFFERENCES WITH DNSC08 } \\
\hline 5 & 0 & 348.6150 & 11.7874 & 23.2749 & 23.3298 & 0 & 346.3390 & 12.2395 & 24.4446 & 24.4914 \\
\hline 10 & 0 & 308.4770 & 11.5057 & 22.2405 & 22.2897 & 0 & 310.2370 & 12.1125 & 23.6236 & 23.6631 \\
\hline 20 & 0 & 252.8430 & 10.8155 & 20.6987 & 20.7308 & 0 & 310.2920 & 11.7846 & 22.5913 & 22.6142 \\
\hline 50 & 0 & 212.4040 & 8.8611 & 16.8459 & 16.8512 & 0 & 297.7190 & 11.0805 & 20.4343 & 20.4361 \\
\hline 70 & 0 & 172.1580 & 7.5738 & 14.0851 & 14.0865 & 0 & 276.7650 & 10.5983 & 19.0166 & 19.0165 \\
\hline 100 & 0 & 167.0650 & 5.8523 & 10.7014 & 10.7018 & 0 & 258.1720 & 10.2891 & 17.8557 & 17.8558 \\
\hline 125 & 0 & 138.8440 & 4.7927 & 8.5216 & 8.5218 & 0 & 252.8610 & 10.4798 & 17.6925 & 17.6926 \\
\hline 150 & 0 & 113.5930 & 4.0107 & 6.7750 & 6.7754 & 0 & 250.6440 & 10.8684 & 14.2548 & 17.9254 \\
\hline 170 & 0 & 92.2770 & 3.5477 & 5.7136 & 5.7140 & 0 & 249.7620 & 11.2488 & 18.2502 & 18.2504 \\
\hline 200 & 0 & 62.1870 & 3.0819 & 4.6656 & 4.6662 & 0 & 249.0740 & 11.7785 & 18.7582 & 18.7583 \\
\hline \multicolumn{11}{|c|}{ DIFFERENCES WITH DTU10 } \\
\hline 5 & 0 & 348.6070 & 11.7072 & 23.2343 & 23.2896 & 0 & 346.3310 & 12.1452 & 24.3993 & 24.4464 \\
\hline 10 & 0 & 308.4700 & 11.4225 & 22.1979 & 22.2474 & 0 & 310.2450 & 12.0174 & 23.5760 & 23.6158 \\
\hline 20 & 0 & 252.8400 & 10.7269 & 20.6533 & 20.6858 & 0 & 310.3000 & 11.6885 & 22.5412 & 22.5644 \\
\hline 50 & 0 & 212.3900 & 8.7482 & 16.7882 & 16.7936 & 0 & 297.7270 & 10.9796 & 20.3741 & 20.3760 \\
\hline 70 & 0 & 172.1390 & 7.4372 & 14.0111 & 14.0125 & 0 & 276.7730 & 10.4892 & 18.9458 & 18.9457 \\
\hline 100 & 0 & 167.0800 & 5.6660 & 10.5917 & 10.5921 & 0 & 258.1800 & 10.1564 & 17.7636 & 17.7636 \\
\hline 125 & 0 & 138.8590 & 4.5564 & 8.3710 & 8.3713 & 0 & 252.8690 & 10.3391 & 17.5839 & 17.5840 \\
\hline 150 & 0 & 113.5940 & 3.7252 & 6.5701 & 6.5704 & 0 & 250.6520 & 10.7228 & 17.8039 & 17.8040 \\
\hline 170 & 0 & 92.2780 & 3.2265 & 5.4573 & 5.4578 & 0 & 249.7700 & 11.1043 & 18.1217 & 18.1219 \\
\hline 200 & 0 & 62.1880 & 2.7123 & 4.3310 & 4.3317 & 0 & 249.0820 & 11.6383 & 18.6229 & 18.6231 \\
\hline \multicolumn{11}{|c|}{ DIFFERENCES WITH DTU13 } \\
\hline 5 & 0 & 350.2330 & 11.6675 & 22.2707 & 23.3579 & 0 & 347.9570 & 12.1400 & 24.5701 & 24.6171 \\
\hline 10 & 0 & 312.1450 & 11.3855 & 22.2707 & 22.3204 & 0 & 313.5640 & 12.0143 & 23.7525 & 23.7922 \\
\hline 20 & 0 & 257.2320 & 10.7009 & 20.7285 & 20.7611 & 0 & 313.6190 & 11.6921 & 22.7300 & 22.7532 \\
\hline 50 & 0 & 219.4650 & 8.7557 & 16.8664 & 16.8719 & 0 & 301.0460 & 10.9977 & 20.5883 & 20.5901 \\
\hline 70 & 0 & 166.5080 & 7.4650 & 14.0920 & 14.0935 & 0 & 280.0920 & 10.5305 & 19.1812 & 19.1812 \\
\hline 100 & 0 & 164.4190 & 5.7426 & 10.6873 & 10.6877 & 0 & 278.8940 & 10.2286 & 18.0314 & 18.0314 \\
\hline 125 & 0 & 145.1890 & 4.6737 & 8.4918 & 8.4921 & 0 & 276.4950 & 10.4330 & 17.8713 & 17.8714 \\
\hline 150 & 0 & 123.2060 & 3.8818 & 6.7264 & 6.7268 & 0 & 269.7030 & 10.8333 & 18.1017 & 18.1018 \\
\hline 170 & 0 & 101.4040 & 3.4107 & 5.6467 & 5.6472 & 0 & 262.6930 & 11.2225 & 18.4229 & 18.4230 \\
\hline 200 & 0 & 70.4960 & 2.9302 & 4.5691 & 4.5698 & 0 & 252.8000 & 11.7643 & 18.9257 & 18.9259 \\
\hline \multicolumn{11}{|c|}{ DIFFERENCES WITH DTU15 } \\
\hline 5 & 0 & 348.9100 & 11.5590 & 23.1342 & 23.1895 & 0 & 346.6340 & 11.9887 & 24.2814 & 24.3285 \\
\hline 10 & 0 & 308.4760 & 11.2763 & 22.0960 & 22.1456 & 0 & 309.0050 & 11.8607 & 23.4522 & 23.4920 \\
\hline 20 & 0 & 252.2250 & 10.5877 & 20.5520 & 20.5844 & 0 & 304.6270 & 11.5340 & 22.4140 & 22.4372 \\
\hline 50 & 0 & 208.2050 & 8.6413 & 16.6919 & 16.6972 & 0 & 292.0540 & 10.8328 & 20.2424 & 20.2442 \\
\hline 70 & 0 & 171.1570 & 7.3521 & 13.9179 & 13.9193 & 0 & 271.1000 & 10.3493 & 18.8110 & 18.8109 \\
\hline 100 & 0 & 165.7980 & 5.6303 & 10.5201 & 10.5205 & 0 & 252.5070 & 10.0348 & 17.6365 & 17.6365 \\
\hline 125 & 0 & 137.5770 & 4.5703 & 8.3355 & 8.3358 & 0 & 247.1960 & 10.2385 & 17.4707 & 17.4709 \\
\hline 150 & 0 & 111.1570 & 3.7895 & 6.5850 & 6.5853 & 0 & 244.9790 & 10.6402 & 17.7045 & 17.7047 \\
\hline 170 & 0 & 89.8410 & 3.3280 & 5.5211 & 5.5215 & 0 & 244.0970 & 11.0320 & 18.0314 & 18.0316 \\
\hline 200 & 0 & 59.7510 & 2.8613 & 4.4724 & 4.4730 & 0 & 243.4090 & 11.5763 & 18.5428 & 18.5430 \\
\hline \multicolumn{11}{|c|}{ DIFFERENCES WITH DTU17 } \\
\hline 5 & 0 & 350.3910 & 11.6009 & 23.2336 & 23.2891 & 0.0010 & 348.1150 & 12.0539 & 24.4812 & 24.5283 \\
\hline 10 & 0 & 312.1410 & 11.3150 & 22.1999 & 22.2496 & 0 & 312.6700 & 11.9294 & 23.6663 & 23.7060 \\
\hline 20 & 0 & 256.3710 & 10.6225 & 20.6542 & 20.6868 & 0 & 309.3880 & 11.6033 & 22.6375 & 22.6607 \\
\hline
\end{tabular}


Table 3 (continued)

\begin{tabular}{|c|c|c|c|c|c|c|c|c|c|c|}
\hline \multicolumn{6}{|c|}{ GECO } & \multicolumn{5}{|c|}{ GO_CONS_GCF_2_DIR_R5 } \\
\hline 50 & 0 & 215.5590 & 8.6654 & 16.7867 & 16.7921 & 0 & 296.8150 & 10.9075 & 20.4869 & 20.4887 \\
\hline 70 & 0 & 166.4850 & 7.3694 & 14.0078 & 14.0092 & 0 & 275.8610 & 10.4359 & 19.0743 & 19.0742 \\
\hline 100 & 0 & 163.5130 & 5.6365 & 10.5937 & 10.5941 & 0 & 274.0410 & 10.1281 & 17.9150 & 17.9150 \\
\hline 125 & 0 & 140.3360 & 4.5579 & 8.3858 & 8.3861 & 0 & 271.6420 & 10.3310 & 17.7473 & 17.7474 \\
\hline 150 & 0 & 118.3530 & 3.7592 & 6.6063 & 6.6067 & 0 & 264.8500 & 10.7342 & 17.9735 & 17.9737 \\
\hline 170 & 0 & 96.5510 & 3.2860 & 5.5156 & 5.5161 & 0 & 257.8400 & 11.1273 & 18.2932 & 18.2934 \\
\hline 200 & 0 & 65.6430 & 2.8067 & 4.4234 & 4.4241 & 0 & 248.1700 & 11.6721 & 18.7949 & 18.7950 \\
\hline \multicolumn{11}{|c|}{ DIFFERENCES WITH SIO V29.1 } \\
\hline 5 & 0 & 351.0390 & 11.7486 & 23.2043 & 23.2683 & 0 & 348.7630 & 12.1806 & 24.3399 & 24.3950 \\
\hline 10 & 0 & 310.8190 & 11.4875 & 22.1813 & 22.2393 & 0 & 311.3480 & 12.0734 & 23.5546 & 23.6018 \\
\hline 20 & 0 & 249.4310 & 10.8275 & 20.6520 & 20.6916 & 0 & 289.4860 & 11.7659 & 22.5519 & 22.5809 \\
\hline 50 & 0 & 201.0600 & 8.9622 & 16.8724 & 16.8813 & 0 & 281.7530 & 11.0882 & 20.4728 & 20.4767 \\
\hline 70 & 0 & 167.1770 & 7.7522 & 14.2008 & 14.2045 & 0 & 258.5140 & 10.6466 & 19.1186 & 19.1193 \\
\hline 100 & 0 & 167.1530 & 6.2084 & 11.0187 & 11.0209 & 0 & 249.5250 & 10.4269 & 18.0848 & 18.0848 \\
\hline 125 & 0 & 167.1820 & 5.2943 & 9.0692 & 9.0714 & 0 & 247.1260 & 10.6818 & 18.0321 & 18.0320 \\
\hline 150 & 0 & 167.1940 & 4.6446 & 7.6041 & 7.6066 & 0 & 240.3340 & 11.1222 & 18.3496 & 18.3496 \\
\hline 170 & 0 & 167.2110 & 4.2739 & 6.7870 & 6.7898 & 0 & 233.3240 & 11.5304 & 18.7213 & 18.7212 \\
\hline 200 & 0 & 167.2480 & 3.9213 & 6.0694 & 6.0726 & 0 & 228.2680 & 12.0808 & 15.0149 & 19.2715 \\
\hline
\end{tabular}

The bold values indicate the lowest values of the RMSE between the altimetry-derived gravity anomalies compared with the global marine gravity anomalies models from DNSC08, DTU10, DTU13, DTU15, DTU17, and Sandwell V29.1

Table 4 The statistical analysis of altimetry-derived gravity anomaly before and after cross-validation procedure (units are mGal)

\begin{tabular}{|c|c|c|c|c|c|}
\hline & Min & Max & Average & Std Dev & RMSE \\
\hline \multicolumn{6}{|c|}{ DIFFERENCES WITH DNSC08 } \\
\hline Before & 0 & 62.187 & 3.0819 & 4.331 & 4.6662 \\
\hline After & 0 & 55.712 & 3.0515 & 4.2465 & 4.5886 \\
\hline \multicolumn{6}{|c|}{ DIFFERENCES WITH DTU10 } \\
\hline Before & 0 & 62.188 & 2.7123 & 4.331 & 4.3317 \\
\hline After & 0 & 53.162 & 2.6803 & 4.2465 & 4.2472 \\
\hline \multicolumn{6}{|c|}{ DIFFERENCES WITH DTU13 } \\
\hline Before & 0 & 70.496 & 2.9302 & 4.5691 & 4.5698 \\
\hline After & 0 & 70.496 & 2.8976 & 4.486 & 4.4868 \\
\hline \multicolumn{6}{|c|}{ DIFFERENCES WITH DTU15 } \\
\hline Before & 0 & 59.751 & 2.8613 & 4.4724 & 4.473 \\
\hline After & 0 & 51.617 & 2.8306 & 4.3935 & 4.3942 \\
\hline \multicolumn{6}{|c|}{ DIFFERENCES WITH DTU17 } \\
\hline Before & 0 & 65.643 & 2.8067 & 4.4234 & 4.4241 \\
\hline After & 0 & 65.643 & 2.774 & 4.338 & 4.3388 \\
\hline \multicolumn{6}{|c|}{ DIFFERENCES WITH SIO V29.1 } \\
\hline Before & 0 & 167.248 & 3.9213 & 6.0694 & 6.0726 \\
\hline After & 0 & 167.248 & 3.8936 & 6.0168 & 6.0202 \\
\hline
\end{tabular}

Boergens et al. (2018) state that single-mission altimetry data are spatially and temporally limited. Additionally, only missions with a short-repeat orbit such as
Envisat, Jason-2 or SARAL, provide time series of sea level variation directly. As a trade-off, long or non-repeat orbit missions such as CryoSat-2 provide a very dense spatial resolution, but their repeat time is insufficient for extracting time series. As a result, multi-mission altimetric data allows for improved spatial and temporal resolution. This is the reason gravity anomalies relative to SIO V29.1 provide high RMSE.The map of the final product is illustrated in Fig. 9.

\section{Conclusion}

Determination of marine gravity anomaly with high resolution and high accuracy is vital for various implementations. Hence, the main focus of this study is to determine and optimise the altimetry-derived gravity anomaly over Malaysian seas. The 2D FFT method has been implemented to estimate and compute marine gravity anomalies with $0.06^{\circ}$ grid resolution for the Malaysian seas using along-track altimeter mean sea surface data. The satellite-only and combined solutions model GGM from GO_CONS_GCF_2_DIR_R5 and GECO are implemented to derive residual sea surface height. Then, the combined full-spectrum gravity anomaly are utilised using the remove-compute-restore technique.

Hence, after the evaluation and verification procedure with the global marine gravity anomaly models, the analyses found that the altimetry-derived gravity anomaly presents RMSE value of $\pm 4.3317 \mathrm{mGal}$ to $\pm 6.0726 \mathrm{mGal}$. 


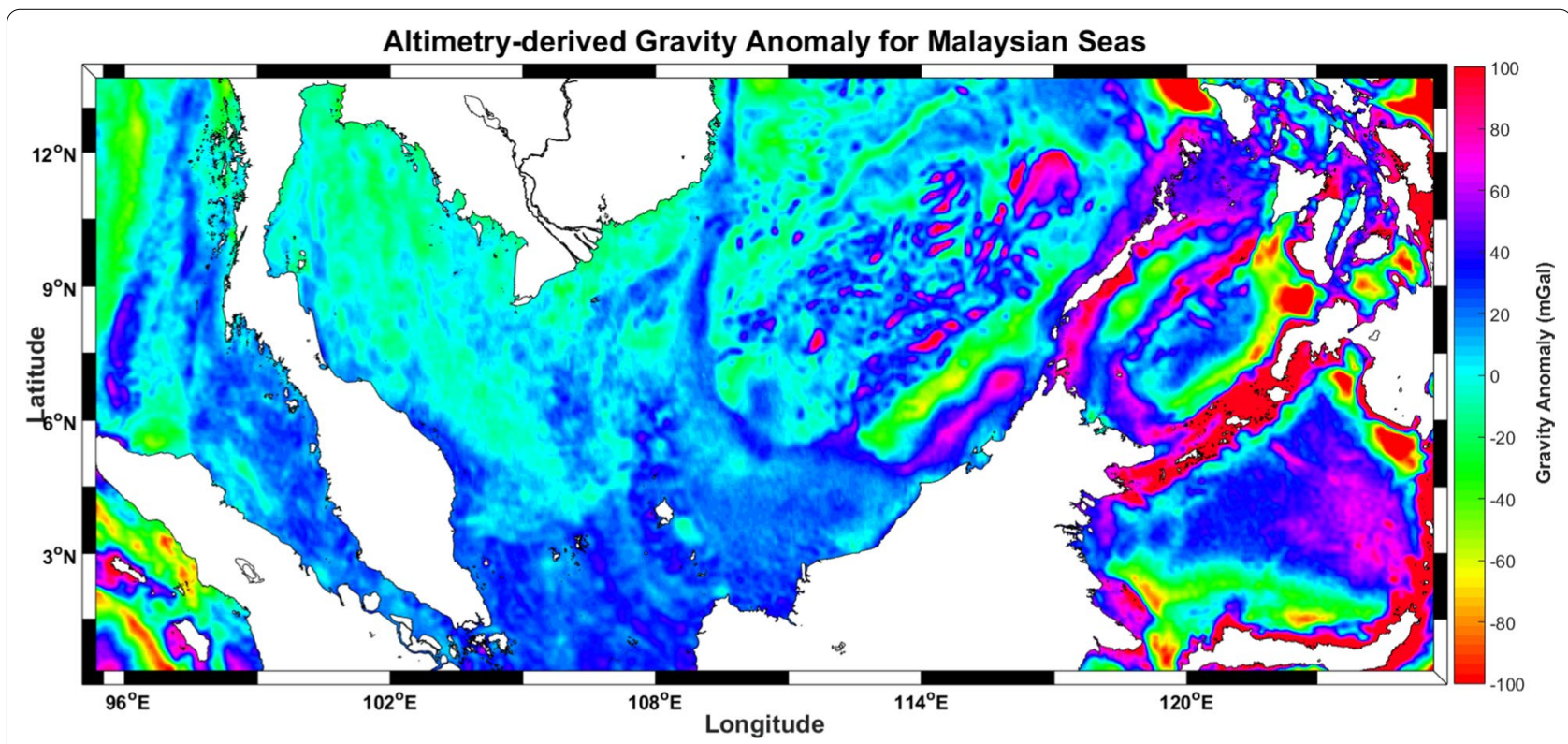

Fig. 9 Altimetry-derived gravity anomaly using along-track data over Malaysian seas

After performing the cross-validation procedure, the RMSE value decreased by approximately $\pm 0.0524 \mathrm{mGal}$ to $0.0845 \mathrm{mGal}$. Thus, the final output provides the altimetry-derived gravity anomaly model over Malaysian seas with good accuracy based on RMSE values of \pm 4.2472 $\mathrm{mGal}$ to $\pm 6.0202 \mathrm{mGal}$.

To compute and develop the altimetry-derived gravity anomaly model with good quality and accuracy, evaluation of the optimal and appropriate GGM model with terrestrial data, such as airborne-derived gravity data, is necessary to align them with regional terrestrial gravity data. Therefore, in the future, along-track altimetry data can be implemented directly in the process of estimating marine gravity anomaly using vertical deflection technique without concerning about the accuracy of the GGM in the region.

\section{Acknowledgements}

The authors would like to acknowledge the Ministry of Higher Education (MOHE) under the Fundamental Research Grant Scheme (FRGS) Fund, Reference Code: FRGS/1/2020/WAB07/UTM/02/3 (UTM Vote Number: R.J130000.7852.5F304) for funding this study.

\section{Authors' contributions}

All seven authors contributed to this paper. The first and second authors, NMZ and $A H M D$, contribute almost the whole paper by providing the idea of the whole structure of this study. AHO and MFP help to guide and drive the study towards the right path in achieving the objectives. NMA is also responsible for paper proofing before the final manuscript is sent to the language editor for a thorough proofreading process. MHH and NAZY provide technical support in the methodology and writing of the manuscript. Conclusively, all authors give their effort for this manuscript submission, whether directly or indirectly. All authors read and approved the final manuscript.

\section{Author details}

${ }^{1}$ Geospatial Imaging and Information Research Group (GI2RG), Faculty of Built Environment and Surveying, Universiti Teknologi Malaysia, 81310 Skudai, Johor, Malaysia. ${ }^{2}$ Geoscience and Digital Earth Centre (INSTeG), Faculty of Built Environment and Surveying, Universiti Teknologi Malaysia, 81310 Skudai, Johor, Malaysia. ${ }^{3}$ Geomatics Innovation Research Group (GnG), Faculty of Built Environment and Surveying, Universiti Teknologi Malaysia, 81310 Skudai, Johor, Malaysia. ${ }^{4}$ Faculty of Civil Engineering and Built Environment, Universiti Tun Hussein Onn Malaysia, 86400 Parit Raja, Johor, Malaysia. ${ }^{5}$ Environment and Climate Change Reseach Group (ECCG), Faculty of Architecture, Universiti Teknologi MARA, Planning \& SurveyingPerlis, Arau Campus, 02600 Arau, Perlis, Malaysia.

Received: 4 May 2021 Accepted: 13 January 2022

Published online: 09 February 2022

\section{References}

Andersen OB (2013) Marine Gravity and Geoid from Satellite Altimetry. In: Sanso F, Sideris MG (eds) Geoid Determination: Theory and Methods. Springer, Heidelberg, pp 401-451

Andersen OB, Knudsen P (1998) Global marine gravity field from the ERS-1 and Geosat geodetic mission altimetry. J Geophys Res 103(C4):8129-8137 Andersen, O. B., G. Piccioni, L. Stenseng, and P. Knudsen, 2015: The DTU15 Mean Sea Surface and Mean Dynamic Topography-Focusing on Arctic Issues and Development." in Oral Presentation, in the 2015 OSTST Meeting, Virginia, USA. Editors P. Bonnefond, J. Willis, and Reston https://meeti ngs.aviso.altimetry.fr/fileadmin/user_upload/tx_ausyclsseminar/files/ OSTST2015/GEO-03-Andersen_MSSH_OSTST.pdf (Accessed October 29, 2020)

Andritsanos VD (2000) Optimum combination of terrestrial and satellite data with the use of spectral techniques for applications in geodesy and oceanography. Doctor Philosophy. Department of Geodesy \& Surveying School of Rural and Surveying Engineering Faculty of Engineering The Aristotle University of Thessaloniki

Barthelmes F, Köhler W (2012) International Centre for Global Earth Models (ICGEM). J Geodesy 86(10):932-934

Barthelmes F (2013) Definition of functionals of the geopotential and their calculation from spherical harmonic models. Scientific technical Rep 
STR09/02. German Research Centre for Geosciences (GFZ), Potsdam, Germany

Bingham C, Godfrey M, Tukey J (1967) Modern techniques of power spectrum estimation. IEEE Trans Audio Electroacoustic 15(2):55-66

Bjerhammar A (1973) Theory of Errors and Generalized Matrix Inverses. Elsevier

Boergens E, Dettmering D, Seitz F (2019) Observing water level extremes in the Mekong River Basin: The benefit of long-repeat orbit missions in a multi-mission satellite altimetry approach. J Hydrolo. 570:463

Bogusz J, Brzezinski A, Kosek W, Nastula J (2015) Earth rotation and geodynamics. Geodesy Cartography 64(2):201-242. https://doi.org/10.1515/geoca rt-2015-0013

Bracewell RN (2000) The Fourier Transform and Its Applications, 3rd edn. McGraw-Hill, New York

Bruinsma SL, Forste C, Abrikosov O, Marty JC, Rio MH, Mulet S, Bonvalot S (2013) The new ESA satellite-only gravity field model via the direct approach. Geophys Res Lett 40(14):3607-3612. https://doi.org/10.1002/ grl.50716

Din AHM, Ses S, Omar K, Naeije M, Yaakob O, Pa'suya MF, (2014) Derivation of sea level anomaly based on the best range and geophysical corrections for Malaysian seas using radar altimeter database system (RADS). Jurnal Teknologi 71(4):83-91. https://doi.org/10.11113/jt.v71.3830

Din AHM, Zulkifli NA, Hamden MH, Aris WAW (2019) Sea level trend over Malaysian seas from multi-mission satellite altimetry and vertical land motion corrected tidal data. Adv Space Res 63(11):3452-3472. https://doi. org/10.1016/j.asr.2019.02.022

Fan D, Li S, Li X, Yang J, Wan X (2021) 2021: Seafloor Topography Estimation from Gravity Anomaly and Vertical Gravity Gradient Using Nonlinear Iterative Least Square Method. Remote Sens 13:64. https://doi.org/10.3390/ rs13010064

Forsberg R, Tscherning CC (2008) An overview manual GRAVSOFT Geodetic Gravity Field Modelling Programs

Geisser S, Eddy WF (1979) A predictive approach to model selection. J Am Stat Assoc 74(365):153-160

Gilardoni M, Reguzzoni M, Sampietro D (2016) GECO: a global gravity model by locally combining GOCE data and EGM2008. Stud Geophys Geod 60:228-247. https://doi.org/10.1007/s11200-015-1114-4

Hamden MH, Din AHM, Wijaya DD, Yusoff MYM, M. F. Pa'suya, (2021) Regional mean sea surface and mean dynamic topography models around malaysian seas developed from 27 years of along-track multi-mission satellite altimetry data. Front Earth Sci 9:665876. https://doi.org/10.3389/ feart.2021.665876

Hamid AIA, Din AHM, Hwang C, Khalid NF, Tugi A, Omar KM (2018) Contemporary sea level rise rates around Malaysia: Altimeter data optimization for assessing coastal impact. J Asian Earth Sci 166:247-259. https://doi.org/ 10.1016/j.jseaes.2018.07.034

Haxby WF, Karner GD, Labrecque JL (1983) Digital images of combined oceanic and continental data sets and their use in tectonic studies. EOS Trans Am Geophys Union 64:995-1004

Hwang C (1998) Inverse Vening Meinesz formula and deflection-geoid formula: applications to the predictions of gravity and geoid over the South China Sea. J Geod 72(5):304-312

Karpik AP, Kanushin VF, Ganagina IG, Goldobin DN, Kosarev NS, Kosareva AM (2016) Evaluation of recent Earth's global gravity field models with terrestrial gravity data. Contributions Geophys Geodesy 46(1):1-11. https:// doi.org/10.1515/congeo-2016-0001

Kiamehr R (2010) Practical Concepts in Geoid Modelling with Geophysical and Geodynamical Interpretations. LAP Lambert Academic Publishing, Saarbrucken

Knudsen P (1993) Integration of Gravity and Altimetry Data by Optimal Estimation Techniques. In Satellite Altimetry for Geodesy and Oceanography, Lecture Notes in Earth Sciences No 50:453-466

Krige DG (1951) A statistical approach to some basic mine valuation problems on the Witwatersrand. J Chem Metal Mining Soc South Africa 52(6):119-139

Liu L, Jiang X, Liu S, Zheng L, Zang J, Zhang X, Liu L (2016) Calculating the marine gravity anomaly of the South China Sea based on the inverse stokes formula. Earth Environ Sci 46:012062. https://doi.org/10.1088/ 1755-1315/46/1/012062

Moritz H (1972) Advanced Least-Squares Methods, Dept of Geodetic Science, OSU. Report No 175:1972
Nguyen V, Pham V, Nguyen LV, Andersen OB, Forsberg R, Bui DT (2020) Marine gravity anomaly mapping for the Gulf of Tonkin area (Vietnam) using Cryosat-2 and Saral/AltiKa satellite altimetry data. Adv Space Res 66(2020):505-519. https://doi.org/10.1016/j.asr.2020.04.051

Pilz M, Parolai S, Picozzi M, Bindi D (2012) Three-dimensional shear wave velocity imaging by ambient seismic noise tomography. Geophys J Int 189(1):501-512. https://doi.org/10.1111/j.1365-246X.2011.05340.x

Rapp RH (1979) Geos 3 data processing for the recovery of geoid undulations and gravity anomalies. J Geophys Res 84(B8):3784-3792

Salam NA (2005) Kajian Ramalan Kedalaman Laut Menggunakan Anomali Graviti Marin daripada Satelit Radar Altimeter. Msc Thesis. Universiti Teknologi Malaysia

Sandwell DT, Smith WHF (1997) Marine gravity anomaly from Geosat and ERS1 satellite altimetry. J Geophys Res 102(B5):10039-10054

Sandwell DT, Müller RD, Smith WHF, Garcia E, Francis R (2014) New global marine gravity model from CryoSat- 2 and Jason-1 reveals buried tectonic structure. Science 346(6205):65-67. https://doi.org/10.1126/science. 1258213

Scharroo R, Leuliette E, Lillibridge J, Byrne D (2012) RADS: Consistent multimission products. Symposium on 20 Years of Progress in Radar Altimetry, 1, 5-8. http://scholar.google.com/scholar?hl=en\&btnG=Search\&q=intit le:RADS+:+CONSISTENT+MULTI-MISSION+PRODUCTS\#O

Smith SW (2003) "CHAPTER 15 - Moving Average Filters. In: Digital Signal Processing. Smith SW, ed. (Elsevier Science: Newnes Press), 277-284. doi:https://doi.org/10.1016/b978-0-7506-7444-7/50052-2

Sulaiman SA (2016) Gravimetric Geoid Model Determination for Peninsular Malaysia Using Least Squares Modification of Stokes, Doctor Philosophy. Universiti Teknologi Mara, Shah Alam

Tanaka Y, Yu Y, Chao BF (2019) Gravity and geoid changes by the 2004 and 2012 Sumatra earthquakes from satellite gravimetry and ocean altimetry. Terr Atmos Ocean Sci 30:531-540. https://doi.org/10.3319/TAO.2018.10. 24.02

Tziavos IN, Forsberg R, Sideris MG, Andritsanos VD (1997) A comparison of satellite altimetry methods for the recovery of gravity field quantities. In: Forsberg R, Feissel M, Diestrich R (eds) IAG Symposia. Springer, Berlin

Tziavos IN, Forsberg R, Sideris MG (1998) Marine Gravity Field Modelling Using Shjipborne and Geodetic Missions Altimetry Data. Geomatics Research Australasia, No 69:1-18

Urban TJ, Schutz BE, Neuenschwander AL (2008) 2008: A Survey of ICESat Coastal Altimetry Applications: Co Open Ocean Island, and Inland River. Terr Atmos Ocean Sci 19(1-2):1-19. https://doi.org/10.3319/TAO.2008. 19.1-2.1(SA)

Vergos GS (2002) Sea Surface Topography, Bathymetry and Marine Gravity Field Modelling, UCGE Reports Number 20157. Univeristy of Calgary, Canada

Vermeer M (1992) A frequency domain approach to optimal geophysical gridding. Manuscr Geodaet 17:141-154

Wu Y, He X, Luo Z, Shi H (2021) An Assessment of Recently Released HighDegree Global Geopotential Models Based on Heterogeneous Geodetic and Ocean Data. Front Earth Sci 9:749611. https://doi.org/10.3389/feart. 2021.749611

Yahaya NAZ, Musa TA, Omar KM, Din AHM, Omar AH, Tugi A, Yazid NM (2016) Mean Sea Surface (MSS) Model Determination for Malaysian Seas Using Multi-mission Satellite Altimeter. Arch Photogramm Remote Sens Spat Inf Sci Int 42:247-252. https://doi.org/10.5194/isprs-archi ves-XLII-4-W1-247-2016

Yahaya NAZ, Musa TA, Omar KM, Din AHM, Omar AH, Tugi A, Yazid NM, Abdullah NM, Wahab MIA (2016) Mean sea surface (MSS) model determination for Malaysian seas using multi-mission satellite altimeter. International Archives of the Photogrammetry. Rem Sens Spatial Inform Sci 42:247252. https://doi.org/10.5194/isprs-archives-XLII-4-W1-247-2016

Yazid NM, Din AHM, Omar KM, Som ZAM, Omar AH, Yahaya NAZ, Tugi A (2016) Marine Geoid Undulation Assessment over South China Sea Using Global Geopotential Models and Airborne Gravity Data, Int. Arch. Photogramm. Remote Sens. Spatial Inf. Sci. 4:253-263

Yuan J, Guo J, Liu X, Zhu C, Niu Y, Li Z (2020) Mean Sea Surface Model over China Seas and its Adjacent Ocean Established with the 19-year Moving Average Method from Multi-Satellite Altimeter Data. Continental Shelf Res 192:104009. https://doi.org/10.1016/..csr.2019.104009

Zhang S, Sandwell DT, Jin T, Li D (2016) Inversion of marine gravity anomalies over southeastern China seas from multi-satellite altimeter vertical 
deflections. J Appl Geophys 137(2017):128-137. https://doi.org/10.1016/j. jappgeo.2016.12.014

Zulkifle MI, Din AHM, Hamden MH, Adzmi NHM (2019) Determination of a

localized mean sea surface model for Malaysian seas using multi-mission

Satellite Altimeter. ASM Science Journal 12(2):81-89

\section{Publisher's Note}

Springer Nature remains neutral with regard to jurisdictional claims in published maps and institutional affiliations.

\section{Submit your manuscript to a SpringerOpen ${ }^{\circ}$ journal and benefit from:}

- Convenient online submission

- Rigorous peer review

- Open access: articles freely available online

- High visibility within the field

- Retaining the copyright to your article

Submit your next manuscript at $\boldsymbol{\nabla}$ springeropen.com 